\title{
Limited airway narrowing: why doesn't everyone have asthma?
}

\author{
A. James*
}

At the 27th Aspen Lung Conference in 1984, MACKLEM [1] posed a number of questions relevant to the understanding of the excessive airway narrowing that occurs in asthma. His discussion was based upon two apparently contradictory observations: 1) that, in vitro, maximally stimulated airway smooth muscle is capable of shortening isotonically by up to $80 \%$ of its optimal resting length [2], a degree of shortening which, were it to occur around the perimeter of an airway, would invariably result in airway closure; and 2) that in nonasthmatic subjects, there is limitation of airway narrowing in response to maximal doses of inhaled bronchoconstricting agonists $[3,4]$. He proposed that powerful inhibitory mechanisms limited smooth muscle shortening in vivo and that alteration or loss of these mechanisms might result in excessive airway narrowing. He stressed the need to examine the mechanical processes by which airway smooth muscle shortens in vivo and results in airway lumenal narrowing. It was tacitly assumed in this discussion that, in vivo, airway smooth muscle could be maximally stimulated via the airway.

Soon after, Moreno et al. [5] described, in a logical sequence, many factors that might influence the change in the airway resistance that occurs after stimulation of smooth muscle. These factors included: 1) those affecting force development in the smooth muscle, such as the total amount of muscle, its contractility and its lengthtension relationships; 2) those affecting the loads opposing shortening such as the stiffness of the structures within the airway wall, and lung parenchymal recoil; 3) those affecting the amount of lumenal narrowing that occurs as smooth muscle shortens, such as the orientation of smooth muscle in the airway wall, the thickness of the airway wall and the presence of mucus in the lumen; and 4) those affecting overall flow such as branching, total cross-sectional area of airways in parallel and the nature of regional flow (laminar or turbulent). This paper brought into focus much of the previous work on the airway function in relation to the surrounding lung, laid the foundation for a large number of studies from several laboratories quantitatively addressing some of these factors, and has resulted in a useful model of airway mechanics [6]. It was important for pointing out that factors such as a reduction in the loads that oppose muscle shortening or an increase in airway wall thickness

*Dept of Respiratory Medicine, Sir Charles Gairdner Hospital, Verdun Street, Nedlands 6009, Western Australia. could result in excessive airway narrowing without the need to invoke a change in the properties of the airway smooth muscle, and thereby explaining the lack of correlation between in vivo airway responsiveness and in vitro smooth muscle responsiveness [7].

However, the question still remains: what usually limits airway narrowing in vivo? DiNG et al. [8] showed that reducing lung volume, and therefore peribronchial parenchymal recoil, increases the maximal degree of airway narrowing that can be induced by inhaled methacholine. Altering the loads opposing shortening in animal models by softening of cartilage [9] also results in greater maximal airway narrowing. Although these studies demonstrate that airway structure and lung recoil will influence airway narrowing, a number of studies have shown that even at lung volumes above functional residual capacity these factors themselves are unable to prevent airway closure. Gunst et al. [10] showed that the forces of interdependence between the lung parenchyma and the airway wall could not prevent airway closure in isolated dog lobes challenged with $50 \%$ methacholine. WARNER and Gunst [11] repeated these findings and showed that airway closure was not prevented by tidal breathing in isolated lung lobes below transpulmonary pressures of $7.5 \mathrm{cmH}_{2} \mathrm{O}$. Airway narrowing was limited when both lungs were stimulated or when intact animals underwent an inhalation challenge. It is difficult to account for the differences between the results for isolated lobes and both lungs. OKAzAwA et al. [12] demonstrated that maximal airway smooth muscle shortening of $45 \%$, enough to cause airway "closure", could be induced by nebulized carbachol in excised dog lungs inflated to transpulmonary pressures of up to 15 $\mathrm{cmH}_{2} \mathrm{O}$. Recently, we have shown that in the isolated, rat lung, perfused via the pulmonary vasculature both lung tissue recoil and surface forces can affect airway smooth muscle shortening but cannot prevent airway closure (muscle shortening greater than $30 \%$ ) at transpulmonary pressures of $15 \mathrm{cmH}_{2} \mathrm{O}$ or below [13].

In this issue of the Journal, Mitchell and Sparrow [14] have related direct video images of lumenal dimensions, measurements of flow or transmural pressure, and morphometric measurements of airway smooth muscle shortening in isolated, perfused pig airway segments stimulated submaximally with electrical field stimulation (EFS) and acetylcholine (ACh), or maximally with ACh $10^{-2} \mathrm{M}$. They showed that the epithelium is consistently thrown into a number of folds 
during airway narrowing with little variation from airway to airway: $23 \pm 1$ (mean \pm SEM) folds per airway for video counts and $24 \pm 1$ for morphometric counts on fixed tissue. This raises the possibility that the number of epithelial folds may be predetermined by airway structure. A reduction in the number of folds, as discussed by LAMBERT [15], might contribute to excessive airway narrowing in asthma. The study of MitcheLL and SPARROw [14] again shows that airway smooth muscle shortening is dependent on transmural pressure. As transmural pressure was increased from $-8 \mathrm{cmH}_{2} \mathrm{O}$ to 20 $\mathrm{cmH}_{2} \mathrm{O}$ resting muscle length increased, as did the amount of muscle shortening produced by EFS, suggesting a more favourable length-tension relationship. However, despite the greater shortening at higher transmural pressure, the final airway diameter was least at lower transmural pressures $\left(0\right.$ and $\left.-8 \mathrm{cmH}_{2} \mathrm{O}\right)$. With maximal stimulation (ACh $10^{-2} \mathrm{M}$ ) under isobaric conditions and at a driving pressure of $5 \mathrm{cmH}_{2} \mathrm{O}$, flow was zero. Morphometric measurements showed that at the cessation of flow, the airway cross-sectional area decreased by a mean value of $67 \%$ and mean smooth muscle shortening was $32 \%$. If applied to the human airway, this degree of muscle shortening is well within the range that will cause markedly different effects on airway narrowing between airways of varying wall thickness, as observed in normal and asthmatic subjects [16]. The authors point out, however, that models of airway narrowing [6] tend to predict a much smaller effect on airway resistance with this degree of smooth muscle shortening. This is not unexpected, since such models do not take into account the effects of mucus or mucosal folding. The video dimensions corresponded closely to those measured morphometrically, suggesting little change during fixation, and the relationship of lumenal dimensions, measured on the video image, to morphometrically calculated smooth muscle shortening agreed closely with the predicted relationship, taking into account the measured wall thickness. This lends confidence to the use of models to examine the likely effects of airway smooth muscle shortening on airway resistance [6].

Although Mitchell and Sparrow [14] did not maximally stimulate smooth muscle at transmural pressures above $0 \mathrm{cmH}_{2} \mathrm{O}$, they demonstrated that even at that pressure maximal stimulation was necessary to increase airway narrowing from $27 \%$ (with EFS) to a maximum of $48 \%$ change in diameter. This highlights the role of the degree of smooth muscle stimulation in determining maximal airway narrowing. Studies of airway narrowing in humans, of necessity, use the inhaled route. The extent to which airway smooth muscle is maximally stimulated by this route has not been adequately examined. It is possible, therefore, that the limitation of airway narrowing that is observed in nonasthmatic subjects is simply due to an inability to maximally stimulate airway smooth muscle via the airway in vivo. An increase in airway permeability might lead to increased smooth muscle stimulation and excessive airway narrowing, as predicted by the studies in isolated lungs above. There are conflicting data $[17,18]$ regarding the permeability of the airways in asthmatic and nonasthmatic subjects to small particles (99mTC-diethylenetriamine penta-acetate (DTPA)). It has been pointed out that there are a number of structural and functional changes in asthma that might alter the transport of agents across the bronchial epithelium [19], and it has been shown by Mitchell and Sparrow's group that responsiveness of human isolated bronchial segments is closely related to epithelial loss [20]. If the airway inflammation seen in asthma increases the passage of bronchoconstricting stimuli across the epithelial barrier, the increased airway smooth muscle stimulation that may result, in combination with other factors, such as increased smooth muscle and increased airway wall thickness [16], might all contribute to excessive airway narrowing. Viral respiratory infections can cause extensive epithelial damage [21]; however, in normal subjects only modest increases in airway responsiveness are seen [22]. This suggests that epithelial disruption alone will not result in the excessive narrowing that is seen in asthma. On the other hand, since experimental respiratory virus infection can result in excessive airway narrowing in patients with asthma [23], we cannot exclude change in airway permeability/transport as an important contributing mechanism in airways already showing inflammation. There is a need for further studies to examine the factors which affect the delivery of agonist from the airway lumen to the smooth muscle.

Finally, the study of Mitchell and Sparrow [14] demonstrates another mechanism by which smooth muscle shortening might be increased, i.e. by uncoupling of the lumenal surface from the adventitial surface, presumably with the influx of fluid into the airway wall outside the layer of smooth muscle. This was observed by simultaneous imaging of the airway lumenal and adventitial border. It has previously been suggested that such a mechanism might unload airway smooth muscle from the surrounding recoil of the parenchyma or from the afterload of the airway cartilage, resulting in increased smooth muscle shortening $[1,24]$ although there have been few reported direct observations. It is unknown if this phenomenon is confined to the pig, or to airways bathed in fluid, and whether it can occur in disease states such as asthma. Further investigation is certainly warranted.

\section{References}

1. Macklem PT. Bronchial hyporesponsivess. Chest 1985; 87: 158s-159s.

2. Stephens NL, Kroeger E, Mehta JA. Force-velocity characteristics of respiratory airway smooth muscle. $J$ Appl Physiol 1969; 26: 685-692.

3. Woolcock AJ, Salome CM, Yan K. The shape of the dose-response curve to histamine in asthmatic and normal subjects. Am Rev Respir Dis 1984; 130: 71-75.

4. Sterk PJ, Daniel EE, Zamel N, Hargreave FE. Limited maximal airway narrowing in nonasthmatic subjects. Role of neural control and prostaglandin release. Am Rev Respir Dis 1985; 132: 865-870.

5. Moreno RH, Hogg JC, Paré PD. Mechanics of airway 
narrowing. Am Rev Respir Dis 1986; 133: 11711180.

6. Wiggs BR, Bosken C, Paré PD, James AL, Hogg JC. A model of airway narrowing in asthma and in chronic obstructive pulmonary disease. Am Rev Respir Dis 1992; 145: 1251-1258.

7. Armour CL, Lazar NM, Schellenberg RR, et al. A comparison of in vivo and in vitro human airway reactivity to histamine. Am Rev Respir Dis 1984; 129: 907-910.

8. Ding DJ, Martin JG, Macklem PT. Effects of lung volume on maximal methacholine-induced bronchoconstriction in normal humans. J Appl Physiol 1987; 62: 1324-1330.

9. Moreno RH, Lisboa C, Hogg JC, Paré PD. Limitation of airway smooth muscle shortening by cartilage stiffness and lung elastic recoil in rabbits. J Appl Physiol 1993; 75: 738-744.

10. Gunst SJ, Warner DO, Wilson TA, Hyatt RE. Parenchymal interdependence and airway response to methacholine in excised dog lobes. J Appl Physiol 1988; 65: 2490-2497.

11. Warner D, Gunst SJ. Limitation of maximal bronchoconstriction in living dogs. Am Rev Respir Dis 1992; 145: 553-560.

12. Okazawa M, Bai TR, Wiggs BR, Paré PD. Airway smooth muscle shortening in excised canine lung lobes. J Appl Physiol 1993; 74: 1613-1621.

13. James AL, Pearce-Pinto G, Hillman DR. The effects of lung volume and surface forces on maximal airway smooth muscle shortening. J Appl Physiol 1994; (in press).

14. Mitchell HW, Sparrow MP. Video imaging of lumen narrowing; muscle shortening and flow responsiveness in isolated bronchial segments of the pig. Eur Respir $J$ 1994; 7: 1317-1325.

15. Lambert RK. Role of bronchial basement membrane in airway collapse. J Appl Physiol 1991; 71: 666-673.

16. James AL, Paré PD, Hogg JC. The mechanics of airway narrowing in asthma. Am Rev Respir Dis 1989; 139: 242-246.

17. Elwood RK, Kennedy S, Belzberg A, Hogg JC, Paré PD. Respiratory mucosal permeability in asthma. Am Rev Respir Dis 1983; 128: 523-527.

18. Ilowite JS, Bennett WD, Sheetz MS, Broth ML, Nierman DM. Permeability of the bronchial mucosa to ${ }^{99 \mathrm{~m} T c-}$ DTPA in asthma. Am Rev Respir Dis 1989; 139: 11341139.

19. Widdicombe JC. Permeability of the airway mucosa in asthma. Eur Respir J 1992; 4 (Suppl. 13): 139s-147s.

20. Omari TI, Sparrow MP, Mitchell HW. Responsiveness of human isolated bronchial segments and its relationship to epithelial loss. Br J Clin Pharmacol 1993; 35: 357-365.

21. Walsh JJ, Dietlein LF, Low FN, Burch GE, Mogabgab WJ. Bronchotracheal response in human influenza. Arch Intern Med 1961; 108: 376-388.

22. Empey DW, Laitenen LA, Jacobs L, Gold WM, Nadel JA. Mechanisms of bronchial hyperreactivity in normal subjects after upper respiratory infection. Am Rev Respir Dis 1976; 113: 131-139.

23. Cheung D, Dick EC, Timmers MC, Deklerk EPA, Spaan WJM, Sterk PJ. Rhinovirous inhalation causes prolonged excessive airway narrowing to methacholine in asthmatic subjects in vivo. Am J Respir Crit Care Med 1994; 149: A47.

24. Macklem PT. A hypothesis linking bronchial hyperreactivity and airway inflammation: implications for therapy. Ann Allergy 1990; 64: 113-116. 